\title{
A rare case of duodenum perforation after biliary stenting under endoscopic retrograde cholangiopancreatography: a case report
}

\author{
Xingda Wu, Guichen Li, Zhe Liu \\ Department of Pancreatic-Billary Surgery, First Hospital of China Medical University, Shenyang, China \\ Correspondence to: Zhe Liu. Department of Pancreatic-Billary Surgery, First Hospital of China Medical University, Shenyang 110001, China. \\ Email: liuzhe4321@126.com.
}

\begin{abstract}
Duodenal injury under endoscopic retrograde cholangiopancreatography (ERCP) is extremely rare. This study describes a case of duodenum perforation after biliary stenting under ERCP for the first time. A 67-year-old female patient was transferred to the emergency department of First Hospital of China Medical University after experiencing whole abdominal pain for 6 hours. The patient had received a biliary stent placement under ERCP at an outer hospital 6 days previously due to duodenal papillary occupy. During the operation, a small perforation caused by a biliary stent was found at the lateral side of the duodenum, but no biliary stent was found. Duodenal juice was flowing out from the perforation, Then, the perforation was opened obliquely, and an 8-cm portion of the biliary stent was removed. Gastrostomy, jejunostomy, and choledochotomy T-tube drainage procedures were subsequently performed. The patient recovered well and was discharged with the T-tube and the jejunal nutrition tube after 20 days. Four types of perforation under ERCP have been reported in previous literature, and this case report documents a rare complication from biliary stenting under ERCP. This case is different from the previous four types and can be called type V, which give general endoscopic doctors a serious warning.
\end{abstract}

Keywords: Biliary stenting; duodenum perforation; complication; endoscopic retrograde cholangiopancreatography (ERCP); case report

Submitted Sep 28, 2020. Accepted for publication Dec 16, 2020.

doi: 10.21037/atm-20-7595

View this article at: http://dx.doi.org/10.21037/atm-20-7595

\section{Introduction}

Endoscopic retrograde cholangiopancreatography (ERCP) has evolved to become a primary therapeutic intervention which complements less invasive modalities, such as magnetic resonance cholangiopancreatography (MRCP) and endoscopic ultrasonography (EUS). ERCP is expected to continue to play an important role in the management of patients with pancreatic and biliary disease (1-3).

Although ERCP is considered to be safe and effective in trained hands, it is associated with an inherent risk of complications (4). Some complications are specific to ERCP, whereas other complications apply to any endoscopic procedure $(4,5)$. Perforation of the duodenal wall is one of the rare but the most serious complications, with a worse prognosis than other complications (5). Although most perforations can be diagnosed during surgery by observing the seepage of contrast agent, even early surgical treatment still has a high mortality rate (6).

In this study, we present the first described case of duodenum perforation after biliary stenting under ERCP, which is an unusual complication of ERCP.

We present the following article in accordance with the CARE reporting checklist (available at http://dx.doi. org/10.21037/atm-20-7595).

\section{Case presentation}

\section{General information}

A 67-year-old female patient was transferred to the emergency department of our hospital on December 12, 2018, with whole abdominal pain that had lasted for 6 hours.

Six days previously, the patient had visited the local 


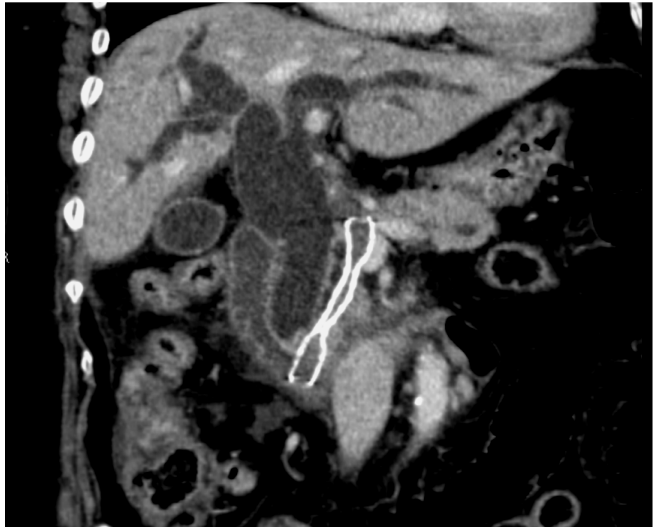

Figure 1 Computed tomography: multiple free gases in the abdominal cavity, the shadow of the biliary stent from the lumen of the descending duodenum to the head of the pancreas, neither in the biliary tract nor in the pancreatic duct.

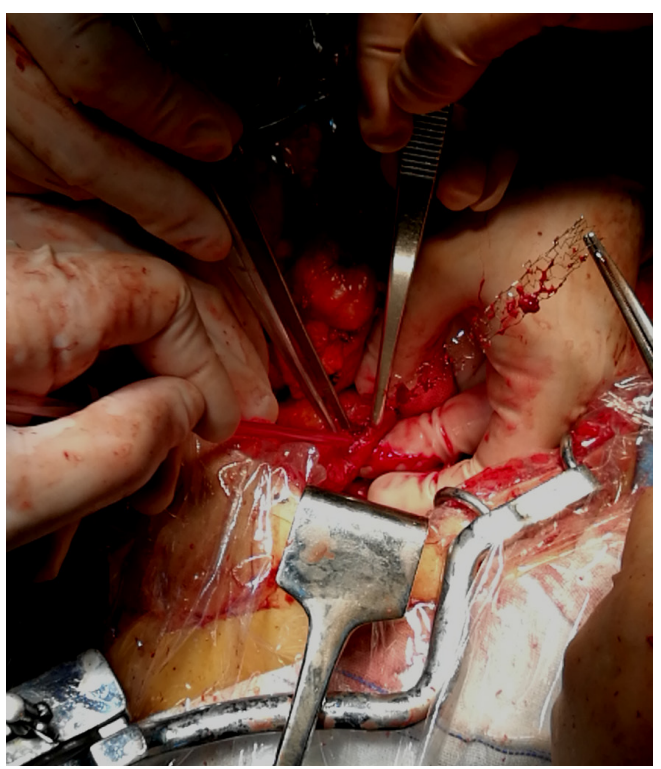

Figure 2 Due to the incarceration of the biliary stent in the pancreatic parenchyma, the removal of the stent from the pancreas by force could have led to further injury. Therefore, most of the biliary stent was carefully removed. Finally, an $8-\mathrm{cm}$ portion of the biliary stent was removed from the duodenal incision with the inserted part of the stent remaining in the pancreas.

hospital with jaundice that had persisted for a week. Duodenoscopy and computed tomography (CT) of the abdomen revealed a mass measuring approximately $2.5 \mathrm{~cm}$ in diameter in the duodenal papilla. After the patient's weak heart and lung function were considered, biliary stent placement under ERCP was performed at the local hospital.

The patient had no surgical history and no history of diabetes mellitus, hypertension, coronary atherosclerotic heart disease, hepatitis, tuberculosis, or other medical histories. The patient had no history of smoking or drinking, and no family history of cancer was reported.

\section{Examination}

Physical examination: heart and lung (-) and normal development of external genitalia.

Abdominal examination: tenderness of the whole abdomen, rebound pain and muscular tonus.

Laboratory examination: WBC: $15.61 \times 10^{9} / \mathrm{L}, \mathrm{NE} \%: 91.7 \%$. HGB: 132 g/L, PLT: $333 \times 10^{9} / \mathrm{L}$, PT: $12.8 \mathrm{~s}$, APTT: $32.1 \mathrm{~s}$, $\mathrm{K}^{+}: 3.16 \mathrm{mmol} / \mathrm{L}, \mathrm{Na}^{+}: 136.4 \mathrm{mmol} / \mathrm{L}$, TBIL: $258.4 \mathrm{mmol} / \mathrm{L}$, DBIL: 237.4 mmol/L, AMS: 164 U/L, LPS: 1,047 U/L.

CT: multiple free gases in the abdominal cavity, the shadow of the biliary stent from the lumen of the descending duodenum to the head of the pancreas, neither in the biliary tract nor in the pancreatic duct (Figure 1 and CT Video 1).

\section{Treatment}

During the operation, a small amount of yellow-white exudate was observed around the liver and duodenum, and a perforation measuring $0.4 \mathrm{~cm}$ in diameter caused by the biliary stent was observed on the antimesenteric border of the duodenal secondary segment. Duodenal juice was flowing out from the perforation.

Next, the duodenal secondary segment was opened obliquely, and the biliary tract at the superior duodenal segment of the common bile duct was opened without observing the biliary stent in the biliary tract. Finally, an $8-\mathrm{cm}$ portion of the biliary stent was gently removed from the duodenal incision with enormous resistance (Figure 2), and gastrostomy, jejunostomy, and choledochotomy T-tube drainage procedures were performed.

\section{Diagnosis}

The patient was diagnosed with perforation of the duodenum after biliary stenting under ERCP in which the biliary stent is displaced into the pancreatic parenchyma without completely passing the duodenal papilla, resulting in excessive rebound force after opening. 


\section{Discharge}

After the operation, the patient was in a stable condition and her jaundice improved gradually. The patient was discharged after 20 days and refused chemotherapy. The discharge orders included: (I) T-tube and the jejunal nutrition tube; (II) combined nutritional support by mouth; (III) comprehensive treatment such as chemotherapy, radiotherapy, biotherapy (during the follow-up and continuous follow-up did not agree with any comprehensive treatment); (IV) return to our hospital for reexamination 1 month later and removal of the drainage tube, as appropriate (the patient was reexamined in the local hospital but did not return to our hospital).

All procedures performed in studies involving human participants were in accordance with the ethical standards of the institutional and/or national research committee(s) and with the Helsinki Declaration (as revised in 2013). Written informed consent was obtained from the patient.

\section{Discussion}

With the development of endoscopic technology, endoscopic sphincterotomy with ERCP has become one of the main treatments for biliary and pancreatic diseases $(7,8)$. To accurately evaluate the prognosis of ERCP, the endoscopic operator must have a clear understanding of the potential complications of ERCP. Perforation after ERCP is among the most serious complications during ERCP and sphincterotomy $(9,10)$. According to one study, 101 patients who underwent ERCP between 1987 and 2003 suffered postoperative perforation, and the perforation-related mortality rate reached $9.9 \%$ (11). Therefore, early diagnosis and treatment of perforation are crucial. The accurate diagnosis and effective treatment of perforation depend on early detection of clinical signs and prompt diagnostic angiography (12).

The female patient in this study suffered a duodenal perforation after biliary stenting under ERCP. She received emergency surgery at our hospital. During the operation, a small amount of yellow-white exudate was observed around the liver and duodenum, and the biliary stent was found to have caused a small perforation measuring $0.4 \mathrm{~cm}$ in diameter on the antimesenteric border of the duodenal secondary segment. Duodenal juice was flowing out from the perforation. The duodenal secondary segment was opened obliquely, and the biliary tract at in the superior duodenal segment of the common bile duct was opened without seeing the biliary stent in the biliary tract. Then, the biliary stent was gently removed from the duodenal incision with enormous resistance.

It was speculated that due to the duodenal papillary cancer, the surgeon who placed the biliary stent could not distinguished the structure of the major duodenal papilla, and placed the stent into the pancreatic parenchyma from the cancerous major duodenal papilla tissue. Due to the toughness of the pancreatic parenchyma, the stent popped out, puncturing the lateral wall of the duodenum. The opening of the stent then resulted in a secondary injury. Because the biliary stent was incarcerated in the pancreatic parenchyma, forceful removal of the stent from the pancreas may have resulted in further injury. Therefore, we carefully removed most of the biliary stent but left the incarcerated portion of the stent in the pancreas (Figure 2). Simultaneously, gastrostomy, jejunostomy, and choledochotomy $\mathrm{T}$-tube drainage procedures were performed. The patient recovered well and was discharged 20 days after surgery.

Duodenal injury after ERCP is extremely rare, and to our knowledge, the current report is the first to describe such a case. In 2000, Stapfer et al. (13) described four types of perforation under ERCP: type I: lateral or lateral duodenal perforation; type II: periampullary injury; type III: wire mesh basket-related distal common bile duct injury; type IV: questionable and not truly a perforation. This case can be defined as a type V perforation (Figure 3). Specifically, type $\mathrm{V}$ is defined as a duodenal perforation caused by biliary stenting under ERCP in which the biliary stent is placed into the pancreatic parenchyma without completely passing the duodenal papilla, resulting in excessive rebound force after opening.

To our knowledge, this is the first report on an unusual complication of ERCP. However, it has some limitations, including the lack of follow-up of the patient, and the postoperative treatment was lacking. The patient refused postoperative chemotherapy until death.

To conclude, this case can serve as an extraordinary lesson in endoscopic therapy for patients suffering from duodenal papillary cancer. We aim for this to be a warning to general endoscopic doctors.

\section{Acknowledgments}

Funding: This study was supported by grants from Liaoning Provincial Department of Education Science Research Project (L2014299) and the National Natural Science 


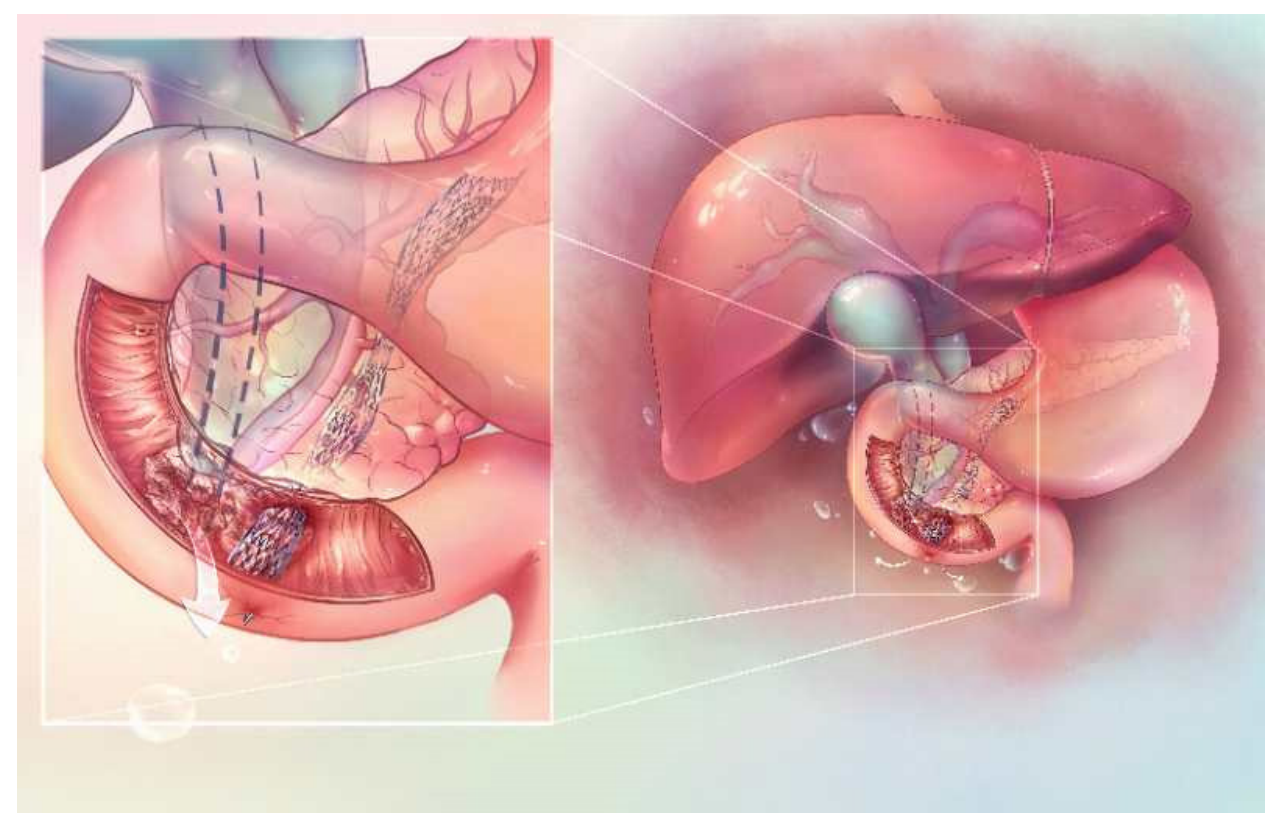

Figure 3 Duodenal perforation after biliary stenting under endoscopic retrograde cholangiopancreatography. The biliary stent had replaced into the pancreatic parenchyma without completely passing the duodenal papilla, resulting in excessive rebound force after opening.

Foundation of China (81572360).

\section{Footnote}

Reporting Checklist: The authors have completed the CARE reporting checklist. Available at http://dx.doi.org/10.21037/ atm-20-7595

Conflicts of Interest: All authors have completed the ICMJE uniform disclosure form (available at http://dx.doi. org/10.21037/atm-20-7595). The authors have no conflicts of interest to declare.

Ethical Statement: The authors are accountable for all aspects of the work in ensuring that questions related to the accuracy or integrity of any part of the work are appropriately investigated and resolved. All procedures performed in studies involving human participants were in accordance with the ethical standards of the institutional and/or national research committee(s) and with the Helsinki Declaration (as revised in 2013). Written informed consent was obtained from the patient.

Open Access Statement: This is an Open Access article distributed in accordance with the Creative Commons
Attribution-NonCommercial-NoDerivs 4.0 International License (CC BY-NC-ND 4.0), which permits the noncommercial replication and distribution of the article with the strict proviso that no changes or edits are made and the original work is properly cited (including links to both the formal publication through the relevant DOI and the license). See: https://creativecommons.org/licenses/by-nc-nd/4.0/.

\section{References}

1. Howard TJ, Tan T, Lehman GA, et al. Classification and management of perforations complicating endoscopic sphincterotomy. Surgery 1999;126:658-63; discussion 664-5.

2. Jin YJ, Jeong S, Kim JH, et al. Clinical course and proposed treatment strategy for ERCP-related duodenal perforation: a multicenter analysis. Endoscopy 2013;45:806-12.

3. Li G, Chen Y, Zhou X, et al. Early management experience of perforation after ERCP. Gastroenterol Res Pract 2012;2012:657418.

4. de Vries JH, Duijm LE, Dekker W, et al. CT before and after ERCP: detection of pancreatic pseudotumor, asymptomatic retroperitoneal perforation, and duodenal diverticulum. Gastrointest Endosc 1997;45:231-5.

5. Ercan M, Bostanci EB, Dalgic T, et al. Surgical outcome of patients with perforation after endoscopic retrograde 
cholangiopancreatography. J Laparoendosc Adv Surg Tech A 2012;22:371-7.

6. Vezakis A, Fragulidis G, Polydorou A. Endoscopic retrograde cholangiopancreatography-related perforations: Diagnosis and management. World J Gastrointest Endosc 2015;7:1135-41.

7. Alfieri S, Rosa F, Cina C, et al. Management of duodenopancreato-biliary perforations after ERCP: outcomes from an Italian tertiary referral center. Surg Endosc 2013;27:2005-12.

8. Machado NO. Management of duodenal perforation postendoscopic retrograde cholangiopancreatography. When and whom to operate and what factors determine the outcome? A review article. JOP 2012;13:18-25.

9. Preetha M, Chung YF, Chan WH, et al. Surgical management of endoscopic retrograde cholangiopancreatography-related perforations. ANZ J Surg 2003;73:1011-4.

Cite this article as: $\mathrm{Wu} \mathrm{X}, \mathrm{Li}$ G, Liu Z. A rare case of duodenum perforation after biliary stenting under endoscopic retrograde cholangiopancreatography: a case report. Ann Transl Med 2020;8(24):1690. doi: 10.21037/atm-20-7595
10. Paspatis GA, Dumonceau JM, Barthet M, et al. Diagnosis and management of iatrogenic endoscopic perforations: European Society of Gastrointestinal Endoscopy (ESGE) Position Statement. Endoscopy 2014;46:693-711.

11. Andriulli A, Loperfido S, Napolitano G, et al. Incidence rates of post-ERCP complications: a systematic survey of prospective studies. Am J Gastroenterol 2007;102:1781-8.

12. Knudson K, Raeburn CD, McIntyre RC Jr, et al. Management of duodenal and pancreaticobiliary perforations associated with periampullary endoscopic procedures. Am J Surg 2008;196:975-81; discussion 981-2.

13. Stapfer M, Selby R, Stain SC, et al. Management of duodenal perforation after endoscopic retrograde cholangiopancreatography and sphincterotomy. Ann Surg 2000;232:191-8.

(English Language Editors: L. Gray and J. Reynolds) 